\title{
The endometrial cancer in Southern Tunisia: Investigation about 52 cases
}

\author{
Kebaili Sahbi ${ }^{*}$, Trigui $K^{1}$, Louati $D^{1}$, Charfi $\mathrm{S}^{2}$, Ben Hlima $\mathrm{S}^{1}$, Daoud $\mathrm{J}^{3}$, Chaabane $\mathrm{K}^{1}$ and Amouri $\mathrm{H}^{1}$ \\ ${ }^{1}$ Obstetrics and Gynecology Department, Hédi Chaker Academic Hospital, Sfax, Tunisia \\ ${ }^{2}$ Anatomopathology Department, Habib bourguiba Academic Hospital, Sfax, Tunisia \\ ${ }^{3}$ Radiotherapy Department, Habib bourguiba Academic Hospital, Sfax, Tunisia
}

\begin{abstract}
To study the epidemiological, clinical, paraclinical and therapeutic caracteristics of this cancer in south Tunisia population, a retrospective descriptive and analytic study was conducted over a period of 12 years from January 1993 until December 2004 on 52 patients carrying endometrial cancer. Diagnosis and therapeutic management were made in the departments of Obstetrics and Gynecology University Hospital HediChaker of Sfax and radiotherapy at the University Hospital Habib Bourguiba of Sfax. The average age of patients was 57.53 years. Menopause was observed in $76.92 \%$ cases. Hypertension, obesity and diabetes were observed, respectively, in $40.38 \%, 26.92 \%$ and $11.53 \%$ of cases. The mean delay of consulting was 8 months. Uterine bleeding was observed in $98.07 \%$ cases. Endometrial b iopsy curettage or directed biopsy was performed in 50 women (96.15\%) including 35 women under hysteroscopy. Histopathological examination was conclusive in 46 patients (92\%) Adenocarcinoma was the most frequent histological type found in 39 cases (84.78\%). Physical examination under general anesthesia was carried out for 44 patients it was normal in $77.27 \%$ of cases. The magnetic resonance imaging was performed in 3 patients. Stage I and II were the most observed stages. Preoperative brachytherapy was achieved only in 30 women. Surgery was indicated in 49 cases (94.23\%). Thirty three patients (63.46\%) received supplemental external radiotherapy. Overall survival at 5 years was $66.8 \%$. Endometrial cancer in associated with many risk factors it must be evoked in front of any abnormal bleeding in aged women. Endometrial biopsy curettage performed under hysteroscopy allows the diagnosis in most cases. Magnetic resonance imaging allows tumorstaging. Treatment is based on the triade brachytherapy, surgery and external post operative radiotherapy. Chemotherapyis added in the therapeutic arsenal in high recidive risk tumor.
\end{abstract}

\section{Introduction}

Endometrial cancer is a malignant tumor originating at the level of the uterine lining. It represents the 3rd cancer in women after breast cancer and colorectal cancers. The typical age-incidence curve for endometrial cancer shows that most cases are diagnosed after the menopause. It is a hormono dependingcancer and exogenous or endogenous hyper oetrogenia is the main risk factor.

The diagnosis of this cancer is based on histological analysis. It is often done in the early stages, therefore prognosis is usually favorable. Endometroidadenocarcinoma represents the most frequent histological type.

The gold standard treatment is surgery and radiotherapy. However, the demonstration of a high metastatic risk in certain subgroups and the positive results of chemotherapy in advanced stages, led to introduction of chemotherapy protocols in the treatment for cancer patients at risk of recurrence.

The objective of this work is to study the epidemiological, clinical, paraclinical and therapeutic caracteristics of this cancerin our population.

\section{Materials and methods}

A retrospective descriptive and analytic study was conducted over a period of 12 years from January 1993 until December 2004 on 52 patientscarrying endometrial cancer. Diagnosis and therapeutic management were made in the departments of Obstetrics and Gynecology University Hospital HediChaker of Sfax and radiotherapy at the University Hospital Habib Bourguiba of Sfax. Data were collected from medical record ofboth departments.

For each patient we generated data of the interview related to risk factors and functional signs and those of clinical examination with a speculum examination, a vaginal, rectal exam, a breast exam and a physical examination looking for signs of metastases or paraneoplastic syndrome. The diagnosis confirmation was obtained with the histopatholgical examination of the endometrial curettage biopsy performed under hysteroscopy since the introduction of the hysteroscope.

A pre therapy locoregional and distance staging is achieved with an examination under general anesthesia, a Magnetic Resonance Imaging (MRI) or an abdominopelvic Computed Tomodensitometry (CT), chest radiography, abdominopelvic ultrasonography, cystoscopy, proctoscopy andtumor markers requested (carbohydrate antigen 125 ,carcinoembryonic antigen) in the presence of associatedadnexal mass. Following this assessment the tumors were classified according

Correspondence to: Kebaili Sahbi, PhD, Obstetrics and Gynecology Department, Hédi Chaker University Hospital, 3029 Sfax, Tunisia, Tel: 0021697556 593; Fax: 00216742432 27; E-mail: kebaili.sahbi@yahoo.fr

Key words: endometrial cancer, endometrial biopsy curettage, adenocarcinoma, extension assessement

Received: January 16, 2015; Accepted: February 10, 2015; Published: February 12,2015 
to the International Federation of Gynecology and Obstetrics (FIGO) in 1988 [1].

The therapeutic regimen was decided after multidisciplnaire consultation including gynecologists and radiotherapists: a preoperative brachytherapy was indicated for tumor stages I or II. The surgery was performed by median incision under the umbilicus and consisted of a complete exploration of the abdominal and pelvic cavity, an extra fascial hysterectomy with oophorectomy and removing of a vaginal cuff of approximately $1.5 \mathrm{~cm}$ in cases of stage I, an extra fascial hysterectomy extended to parameters and paracervix in stages II and III. Pelvic lymphadenectomy was performed in patients with cancer classified beyond the stage IA. Postoperative external radiotherapy was indicated in cases of myometrium invasion exceeding two internal thirds, nodes involvement or anincomplete surgery.

Patient follow-up was done in consultation every 3 months for 2 years then every 6 months for 5 years and annually thereafter. This surveillance was followed clinically and radiologically by chest radiography and abdominopelvic ultrasound.

For each patient a form was fulfilled and entered on the software "Epi Info". The statistical study was descriptive with survival studies using the method of "Kaplan Meier" and analytical comparison of survival curves using the test "Log-rank." Statistical significance was considered for a degree less or equal to $5 \%$

\section{Results}

During the study period we identified 52 patients carrying endometrial cancer. The average age of patients was 57.53 years with extremes ranging from 27 to 76 years? Patients who their age exceeded 50 years were accounted for $80.76 \%$. The average age of menarche was 12.15 years. Early puberty was observed in 2 patients or $3.84 \%$. The average parity was 3.73 , multiparity was observed in $33 \%$ of cases. Menopause was observed in $76.92 \%$ cases. The mean age of menopause was 49.75 years. Late menopause was observed in $20 \%$ of cases.

By analyzing the family history, presence of cancer in the family was noted in $17.3 \%$ of cases ( 9 cases): it was a breast cancer 3 cases, one case of endometrial cancer, one case of colon cancer,two cases of livercancer,one case of leukaemia and one case of myeloma. Family history of diabetes and hypertension were observed respectively in $17.3 \%$ and $13.46 \%$ of cases.

For personal history, hypertension, obesity and diabetes were observed, respectively, in $40.38 \%, 26.92 \%$ and $11.53 \%$ of cases. Tobacco was observed in $9.6 \%$ of cases. Personalhistory of cancer was noted in two patients, one case of breast cancer and one case of liver cancer. Seven point seven percent of patients had used a contraceptive type oestroprogestative. No menopausal patient in our series had received hormonal replacement therapy for menopause. The patient treated for breast cancer, received a standard intervention "Patey" with adjuvant radiotherapy, chemotherapy and surgical castration, it was not put on tamoxifen.

The mean delay of consulting was 8 months and ranged from 15 days to 48 months. Thirty point seven six percent of patients had consulted before threshold of three months, while $13.46 \%$ put more than 12 months to consult. The most frequent reason for consulting was bleedings observed in $98.07 \%$ cases. They were post-menopausal in $78.43 \%$ and peri menopausal in $21.56 \%$ of case. All postmenopausal women showed metrorrhagia. The second symptom was pelvic pain observed in $38.46 \%$ cases. The discovery of metastases has never been a reason for consulting (Table 1).

For the clinical examination, the general condition was maintained at $98.07 \%$ of patients. Hepatomegaly, and lower limb edema was objectified in only one patient. Uterine Bleeding was put in evidence at the speculum examination in $40.38 \%$ of patients. Seven patients had presented with a cervical lesion with positive biopsy (indicating a cervical invasion) in 5 patients or $9.61 \%$ of cases. Vaginal budding lesions were objectified in 3 patients. The biopsy was positive (indicating a vaginal invasion) in only one patient (1.92\%). Vaginal examination was done in 47 patients or $90.38 \%$ of cases (5 patients were virgins). It had objectified an enlargeduterus in $29.78 \%$ of women, a fixed uterus in $4.25 \%$ cases and anextension to vaginal fornix in $6.38 \%$ of patients.

Pelvic ultrasound was performed in all our patients. It had objectified endometrial thickening in $69.23 \%$ and intra cavitary image in $38.46 \%$ of patients ( 20 cases). It allowed in addition to show a lateral uterine mass of probabalyovarian in 8 women of which 3 were suggestive of malignancy. Doppler has been studied for six women with intra cavitarymass; it was in favor of malignancy in 5 cases showing hyper vascularity of the mass (Table 2 ).

Hysteroscopy was performed in 35 patients (67.30\%). It objectified a budding tumor in $54.28 \%$ of cases (19 cases), while $42.85 \%$ of cases it was only a hypertrophy of the endometrium. In $42.1 \%$ of cases, the tumor had a well developedanarchic vascularization, and it was whitish in $36.84 \%$ cases. The tumor was located in $63 \%$ of cases at uterine surfaces, in $26 \%$ at the isthmus and $11 \%$ in the fundus (Table 3 ).

Table 1. Consulting reason.

\begin{tabular}{|l|c|c|}
\hline & Number & $\mathbf{\%}$ \\
\hline Bleedings & 51 & 98.07 \\
\hline Pelvic pain & 20 & 38.46 \\
\hline Leucorrhoea/runny & 8 & 15.38 \\
\hline Altered general condition & 2 & 3.84 \\
\hline Urinary symptoms & 2 & 3.84 \\
\hline Primary infertility & 1 & 1.92 \\
\hline Metastasis & 0 & 0 \\
\hline
\end{tabular}

Table 2.Ultrasonographic data.

\begin{tabular}{|l|c|c|}
\hline & Number & $\mathbf{\%}$ \\
\hline Endometrial thickness & 36 & 69.23 \\
\hline Uterus increased in size & 22 & 42.3 \\
\hline Intra cavitary image & 20 & 38.46 \\
\hline Lateral uterine mass & 8 & 15.38 \\
\hline Uterine fibroma & 4 & 7.69 \\
\hline Effusion of Douglas & 2 & 3.84 \\
\hline
\end{tabular}

Table 3. Hysteroscopy data.

\begin{tabular}{|l|c|c|}
\hline & Number & $\mathbf{\%}$ \\
\hline Aspect & & \\
\hline Normal & 1 & 2.85 \\
\hline Endometrial hypertrophy & 15 & 42.85 \\
\hline Tumoral mass & & 54.28 \\
\hline Vascularisation type & 8 & \\
\hline anarchic & 3 & 42.10 \\
\hline Non developped & 8 & 15.78 \\
\hline Non precised & & 42.10 \\
\hline Color & 7 & \\
\hline Whitish & 4 & 36.84 \\
\hline Chamois & 3 & 21.05 \\
\hline Necrotic-hemorrhagic & 5 & 15.78 \\
\hline Non precised & & 26.31 \\
\hline
\end{tabular}


Hysterosalpingography, performed in 12 patients or $23.07 \%$ of cases, showed a blurred intrauterine irregular defect in all cases.

Endometrial Biopsy Curettage (EPC) or directed biopsy was performed in 50 women $(96.15 \%)$. Two patients did not have this investigation: the first one, 53 years old, was operated by laparotomy for an ovarian tumor (mixed endometroid and mucinous ovarian cystadenocarcinoma) with discovery of a synchronous endometroidcarcinoma of the endometrium on surgical specimens, the second patient of 40 years was operated by a hysterectomy for heavy bleeding with hemodynamic, clinical and biologicalimpact whose final histopathological analysis concluded of an endometrial cancer. Histopathological examination was conclusive in 46 patients (92\%). Adenocarcinoma was the most frequent histological type found in 39 cases $(84.78 \%)$ (Table 4$)$. Well differentiated forms represented $71.8 \%$ of cases. For the 4 patients in who the EPC was inconclusive: two women had simple hyperplasia without atypia, one woman had a tubercular endometritis, these three women were operated later for recurrent metrorrhagia, the fourth patient of 54 years, menopausal, with postmenopausal metrorrhagia had simple hyperplasia with atypia and she was operatedbecause of the degeneration risk of this lesion.

A preoperative staging was performed in 46 patients (for the 6 remaining women the diagnosis of endometrial cancer was made on surgical specimens, the preoperative staging was not performed). The vaginal ultrasound has not been used to study myometrial invasion. Physical examination under general anesthesia (GA) was carried out; jointly by he radiation oncologist and surgeon for 44 patients it was normal in $77.27 \%$ of cases (Table 4). Cystoscopy was performed in all patients $(n=46)$, it showed an invasive bladder in only one patient, whose biopsy concluded to infiltration by low differentiated endometrium adenocarcinoma. Similarly, proctoscopy performed in all cases showed a rectal invasion in only one patient with biopsyproven. An abdominopelvic CT was performed in 8 patients showing a tumor confined to the uterus in 6 cases, one locoregional and paraaortic lymph nodes infiltration in 2 cases and liver metastases in one case. The magnetic resonance imaging (MRI) was performed in 3 patients including 2 who did not haveGA; the data are summarized in the table 4. Intravenous urography was performed in all our patients: it was normal in 43 cases (93.47\%); it showed a bladder parietal rigidity in one case, a ureteral discharge in one case and a unilateral ureterohydronephrosis in one case. An abdominal ultrasound, performed in 46 patients, revealed one case of liver metastasis and one case of unilateral pyelocalyceal dilatation, indicating probably aparametrial invasion. The chest radiograph, performed for all patients in our series, was normal in $98.07 \%$ of cases, and it showed lung metastases in one case. The bone scan was requested for only one patient of 70 years, carriying a well differentiated adenocarcinoma and who complained of left hip pain, it found a degenerative decreased uptake

Table 4. Histological types and grade.

\begin{tabular}{|l|c|c|}
\hline & Number & $\mathbf{\%}$ \\
\hline Adenocarcinoma & 39 & 84.78 \\
\hline Grade I & 28 & 71.8 \\
\hline Grade II & 8 & 20.51 \\
\hline Grade III & 3 & 7.69 \\
\hline Serous papillary carcinoma & 2 & 4.34 \\
\hline Adenoacanthoma & 2 & 4.34 \\
\hline Adenosquamous carcinoma & 1 & 2.17 \\
\hline Adenosarcoma & 1 & 2.17 \\
\hline Transitional cell carcinomas & 1 & 2.17 \\
\hline
\end{tabular}

Table 5. Physical examination under general anesthesia data.

\begin{tabular}{|l|c|c|}
\hline & Number & $\mathbf{\%}$ \\
\hline Normal & 34 & 77.27 \\
\hline Cervical infiltration & 7 & 15.90 \\
\hline Parameters invasion & 6 & 13.63 \\
\hline Vaginal lesion & 3 & 6.81 \\
\hline $\begin{array}{l}\text { Rectovaginal septum } \\
\text { infiltration }\end{array}$ & 1 & 2.27 \\
\hline
\end{tabular}

Table 6. MRI data.

\begin{tabular}{|l|c|c|}
\hline & Number & $\mathbf{\%}$ \\
\hline Myometrium $<50 \%$ & 1 & 33.33 \\
\hline Invasion $\geq 50 \%$ & 2 & 66.66 \\
\hline Parameters infiltration & 1 & 33.33 \\
\hline $\begin{array}{l}\text { Attainment of hail } \\
\text { Pelvic lymph nodes } \\
\text { involvement }\end{array}$ & 1 & 33.33 \\
\hline
\end{tabular}

of the roof of the left acetabulum. Tumour markers (carbohydrate antigen 125 , carcinoembryonic antigen) were required in 8 patients with lateral uterine mass on ultrasound. One woman had a high rate of carbohydrate antigen 125 at 50 international unit; she actually had a synchronous ovarian cancer.

Following these investigations, the tumor was classified preoperatively according to FIGO 1988: In our study $56.52 \%$ of cases were at stage I, $32.60 \%$ at stage II, $4.34 \%$ at stage III and $6.52 \%$ at stage IV (Table 5).

For the treatment, preoperative brachytherapy was indicated for 41 patients but has been achieved only in 30 women given the unavailability of radioactive material or technical difficulties, it was utero vaginal in 14 patients with stage II and vaginal in 16 patients with stage I.

The average time between brachytherapy and surgery was 5 to 6 days. Surgery was indicated in 49 cases $(94.23 \%)$. The three non-operated women had locally advanced tumors: one with a stage IV A, one with metastatic cancer to the lung and liver, and one with stage III C but with an anesthetic risk considered important. The surgical approach was median umbilical in 46 patients (93.87\%), and pfannestielin 3 of 6 patients whose diagnosis was retrospective. Forty patients or $81.63 \%$ had a colpohysterctomy with pelvic lymphadenectomy, 24 patients with tumors classified as stage I, 15 tumors as stage II and one tumor as stage III. The colpohysterctomywas extended to the parameters and paracervix in case of stage II and III. Hysterectomy with oophorectomy was performed in 7 patients (14.28\%) in 2 women with tumors classified stage IA,in 4 patients with negative EPC and in a patient with a tumor classified IVB reaching the hail (hysterectomy of cleanliness). Among the operated patients, $38.77 \%$ had surgery immediately, and $61.22 \%$ had surgery after brachytherapy. Peritoneal cytology performed in 26 patients was negative in all cases.

The final histopathological analysis showed that the most common histological type was adenocarcinoma found in $78.84 \%$ (Table 6). Lymph node dissection had interested 41 patients (83.67\%). This dissection was considered sufficient in 11 patients (26.82\%). Lymph node involvement was observed in $14.63 \%$ of stage I and II; it was noted in $10.71 \%$ of endometroid carcinomas against $23.07 \%$ in the other histological types. The lymph nodes involved $11.11 \%$ of tumors classified degree 1 and 2 and $26.66 \%$ of tumors invading more than half of the myometrium. 
Table 7. Distribution of patients according to preoperative tumor classification.

\begin{tabular}{|c|c|c|}
\hline Stage & Number & $\mathbf{\%}$ \\
\hline I & 26 & 56.52 \\
\hline IIA & 13 & 28.26 \\
\hline IIB & 2 & 4.34 \\
\hline IIIA & 1 & 2.17 \\
\hline IIIB & 0 & 0 \\
\hline IIIC & 1 & 2.17 \\
\hline IVA & 1 & 2.17 \\
\hline IVB & 2 & 4.34 \\
\hline Total & 46 & 100 \\
\hline
\end{tabular}

Table 8. Final tumor staging.

\begin{tabular}{|c|c|c|}
\hline Stage & Number & $\mathbf{\%}$ \\
\hline IA & 8 & 15.38 \\
\hline IB & 11 & 21.15 \\
\hline IC & 5 & 9.61 \\
\hline Total & 24 & 46.15 \\
\hline IIA & 14 & 26.92 \\
\hline IIB & 2 & 3.84 \\
\hline Total & 16 & 30.76 \\
\hline IIIA & 2 & 3.84 \\
\hline IIIB & 0 & 0 \\
\hline IIIC & 7 & 13.46 \\
\hline Total & 9 & 17.3 \\
\hline IVA & 1 & 1.92 \\
\hline IVB & 2 & 3.84 \\
\hline Total & 3 & 5.76 \\
\hline & & \\
\hline
\end{tabular}

After surgery a definitive classification is established: stage I was observed in $46.15 \%$ of cases, stage II in $30.76 \%$, stage III in $17.3 \%$ and stage IV in $5.76 \%$ (Table 7 ).

In our series 33 patients $(63.46 \%)$ received supplemental external radiotherapy. The average delay between surgery and radiotherapy was 81 days with extremes of 34 to 88 days. All these patients had pelvic irradiation; two patients received also paraaorticlymph node irradiation. Radiotherapy was delivered of 40-50 Gray (Gy) in 28 patients (84.84\%) and a dose of $40 \mathrm{~Gy}$ followed by vaginal brachytherapy of $20 \mathrm{~Gy}$ in a patient with a tumor classified as stage IIA. Palliative radiotherapy was given for a tumor invading the rectum (stage IV) at a dose of 20 Gy in 5 sessions. It was combined with chemotherapy in 2 patients, at a dose of $30 \mathrm{~Gy}$ in women with an associated ovarian tumor and at a dose of 44 Gy in unoperated women with tumor classified as stage IIIC (Table 8).

Some complications induced by treatment were observed. In fact the surgery was complicated by a wound of the internal iliac vein and the external iliac artery during pelvic lymph node dissection in one case. No bladder or urethral wound or gastrointestinal were noted. No complication was noticed for the preoperative brachytherapy. However, external beam radiotherapy, although well tolerated, was complicated radioepithelitis by in 16 cases $(48.48 \%)$ with, cystitis in 2 cases and diarrhea in 5 cases. A long-term peritoneal fibrosis was noted in one case.

Immediately after treatment, 3 patients were not evaluable (2 patients lost to follow and one patient who received only supportive care). Of the 49 evaluable patients, 43 were in complete remission (87.75\%), 2 cases of progressive locoregional pursuit, one case with the development of metastasisand 3 patients whose tumors already advanced were partially responsive to treatment.
During the study period 5 patients $(9.61 \%)$ were lost to follow; all in complete remission, with a mean duration of follow-up was 82 months. The number of women who died was 19 (36.53\%) with a mean a mean duration of follow of 28 months from the end of treatment, including 16 deaths were directly related to the neoplastic disease. Patients in complete remission $(n=28)$ accounted for $53.84 \%$ with a mean duration of follow of 96 months. Three patients (6.97\%) had loco regional pursuitwith an averagedelay of 23.6 months from the end of treatment. Five patients (11.62\%) developed distant metastases; the average time of onset was 37.8 months. None of these patients had received chemotherapy. And no response for treatment was observed. Death occurred within a mean period of 10 months (2-24 months).

Overall survival at 5 years was $66.8 \%$. We analyzed this rate according to prognostic factors. For age, the survival rate at 5 years was $69 \%$ if age below 60 years and $63 \%$ otherwise. The difference was not significant $(\mathrm{p}=0.41)$. For menopausal status, there was no significant difference if the patient was menopausal or not $(p=0.76)$. Similarly for a consultation period set at three months. On the other hand, the 5-year survival by stage was $87 \%$ for stage I, $71 \%$ for stage II, $22 \%$ for stage III and $0 \%$ for stage IV, the difference was significant. The 5 -year survival was $83 \%$ in patients with no nodal involvement against $32 \%$ among those with lymph node metastasis $(\mathrm{p}<0.0029)$.

\section{Discussion}

Endometrial cancer is increasing in many countries where it has become the most common gynecological cancer in women [1,2]. Indeed in the United States of America, Jemal A [3] reports the occurrence of 40,100 new cases per year in 2008. In Europe in 2006 [4], this cancer was the $3^{\text {rd }}$ women cancer after breast cancer and colorectal cancers. In Tunisia, the incidence of endometrial cancer is difficult to assess given the lack of a specific national registry and data available includes for all uterine corpus cancers: Indeed in the cancer registry in southern Tunisia for years 2000-2002 [5], the incidence of uterine corpus cancer was 2.8 per 100,000 women and it was 4.2 per 100,000 in the years 1997-1999 [6].

Our study was able to specify some risk factors associated with the occurrence of endometrial cancer. First, the age: endometrial cancer is a cancer of oldwomen; the peak of its frequency is between 58 and 62 years [7]. In our series the mean age was 57.53 years. It concerns also menopausal women in 75 to $80 \%$ of cases [8]; this has been well demonstrated in our study where $76.92 \%$ of patients were postmenopausal and only $7.69 \%$ were aged $\leq 40$ years. The occurrence in a young woman of the endometrial cancer is often associated with other risk factors involving nulliparity, obesity, diabetes, gonadal dysgenesis, or Lynch syndrome II.

Nulliparity increases the risk of endometrial cancer by three [9]. Indeed parity seems to be a protective factor of endometrial cancer [10]. Cancer risk was 0.9 (95\% CI: 0.7-1 .1) 0.8 (95\% CI: 0.6-1 .0) and 0.7 (95\% CI, 0.5-0 .8) for patients who had 1, 2 or 3 children [11]. In our study, nulliparity was observed in $33 \%$ of cases.

The 3rd factor is diabetes, found in $11.53 \%$ of our cases. In published series the percentage of women with diabetes varies from 4 to $32 \%$ [12]. The role of diabetes as a risk factor for endometrial cancer is currently being discussed and assumptions to be diverted to insulin resistance and hyperinsulinemia, a study by Bernstein [13] found insulin resistance in $35 \%$ of women without diabetic carriers of endometrial cancer.

Obesity through androgens conversion to estrogens in adipocytes 
and by decreasing the rate of sex hormone-binding globulin in the circulation is a risk factor for endometrial cancer [14]. Obese patients have a risk two to four times more important to develop this type of cancer [15]. In our series, obesity was found in $26.92 \%$ of patients. This rate seems lower than those reported in the literature between $50 \%$ and $80 \%$ of cases [16]; this is explained by the lack of data about this factor in our records.

High blood pressure is a leading risk factor for endometrial cancer especially when associated with obesity [17]. Elwood [18] evaluates to 1.5 the relative risk of this cancer in case of hypertension. The proportion of hypertensive patients in our study was $40.38 \%$ which is consistent with literature data where it is 38 to $40 \%$ [19].

Other factors are discussed in the literature and found with low proportions in our series such as ovarian dystrophy with a rate of $3.84 \%$, hormone replacement therapy and tamoxifen, absent in our patients, atypical hyperplasia of the endometrium for which there was only one case.

Finally, it is important to mention that there are familial forms of endometrial cancer that may point to a genetic susceptibility to develop this cancer. These forms are included in certain syndromes such as Lynch syndrome II (combined colorectal, endometrial, ovarian, and breast cancers) and heriditary non-polyposis colorectal cancersydrome [20].

The mean delay of consulting in the serieof Kimura comprising 304 women was less than one month in $35.53 \%$ and more than 06 months in $26.44 \%$ of patients [21]. In our series, it was 08 months with ahigh extreme of 48 months. Thisretarded delay of consultation can be explained by the lack of information of Tunisian women on the risk factors and signs suggestive of the disease, the problems of shame and modesty which remain an obstacle to the consultation especially in rural areas and economic hardship.

In fact, it is bleeding, whatever its form, which is the the most frequent reason for visiting in most series [22,23] at around 90\%, it was $98.07 \%$ in our series and especially post menopausalmetrorrhagiafound in all our menopausal women. Infact, according to the study of Weber [24], endometrial carcinoma is found in $10-15 \%$ of postmenopausal women with abnormal uterine bleeding. In young women the endometrial cancer is often discovered during a hysteroscopy performed as part of an infertility evaluation or during removal of aendocavitary polyp. Finally, other signs may be included in the circumstances of discovery of an endometrial carcinoma such as pelvic pain or signs of ectopic extension usually indicating an advanced stage of the pathology.

Ultrasonography is the first paraclinic tool to ask in front ofperi or postmenopausal bleeding [25], first it allows the measurement of endometrial thickness. Indeed for many authors a value exceeding $4 \mathrm{~mm}$ in a postmenopausal woman without hormone replacement therapy should be investigated for underlying cancer $[26,27]$. By setting the threshold of $4 \mathrm{~mm}$, ultrasound has a positive predictive value of 63.6 to $98.5 \%$ and a negative predictive value of 96.6 to $97.6 \%$. In our series, endometrialthickening was found in 36 cases or $69.23 \%$. Second, it helps in exploring pelvis and ovaries, in order to detect synchrone tumors.

Hysteroscopy is a key tool in the diagnosis of endometrial cancer. It allows exploration of the endometrial surface and performs biopsies in cases of very limited lesion. The sensitivity of this examination in the diagnosis of endometrial cancer varies between $65.52 \%$ and $100 \%$ depending on the series $[28,29]$. According to Clark [30], hysteroscopy suspect increases the likelihood of endometrial cancer in $71.8 \%$, whereas a negative hysteroscopy reduced the probability to $0.6 \%$. In our series we have objectified endometrial hypertrophy in $42.85 \%$ of cases and tumor mass in $54.28 \%$ cases.

The EPC was performed in 50 women(96.15\%) in our series. It was guided by hysteroscopy in 35 patients. Pathological examination of the product of EPC was successful in $92 \%$ cases which is consistent with the literature [31].

Currently, staging may be limited to an abdominopelvic MRI. Cystoscopy, proctoscopy and intravenous urography are only indicated in case of abnormality on MRI. This technique allows studying the myometrial invasion degree with a sensitivity and specificity in the literature varying between 50 and $64 \%$ and between 70 and $89 \%$ respectively [32-35] and appreciating the cervical and lymph node invasion [35]. However, physical examination under general anesthesia remains interesting in the clinical evaluation of tumor extension [36], especially for these obese patients who do not let themselves to be examined easily. Therefore we recommend continuing the practice of the examination under general anesthesia, to generalize the implementation of MRI and be limited to chest radiography in pulmonary exploration for tumor staging.

The purpose of this extension assessment is to establish a preoperative staging and guide treatment strategy. However, this staging may be disappointing, with rates of over or under estimations of 13 to $40 \%$ [37,38]. In our series, $56.62 \%$ of women had tumors classified preoperatively in stage I, this figure drops to $46.15 \%$ during the final classification. Our rates seem being low compared to some other studies where stage I is observed in $75 \%$ of cases this is explained by the delayed consulting of our patients.

The standard treatment for endometrial cancer is based on the triad brachytherapy, external beam radiotherapy and surgery. Preoperative brachytherapy is no longer recommended for stage I [31] due to errors in preoperative staging, which can lead to unnecessary radiation and the fact that some studies have shown that the results of preoperative brachytherapy are comparable to that postoperatively. Its major indication is in stage II, where it contributes to improve the tumor local control: vaginal and parametrial [39]. Surgery is a gold standard in the treatment of endometrial cancer. Several approaches have been described: the most classic laparotomy by median incision under the umbilicus that allows acompleteanalysis of the disease as recommended by FIGO [40]. The vaginal route was also proposed but it has limitations in the exploration of the peritoneal cavity and lymph node dissections that is why it is reserved for patients at high surgical risk with an early stage of tumor disease [41]. To overcome the limitations of the vaginal route, the laparoscopic approach was associated, allowing full intra-abdominal exploration, peritoneal cytology, performing peritoneal cytology, an oophorectomy, para-aortic lymphadenectomy and omentectomy. According to some authors, laparoscopic surgery allows an assessment of endometrial cancer as complete as laparotomy with lower morbidity in terms of intraoperative complications and length of hospitalization $[42,43]$. However, it was reported a failure rate of complete surgical treatment by this route of about 5 to $35 \%$ depending on the series, mainly attributed to obesity [44]. For stages I and II, hysterectomy should be at least extrafascialtotal with salpingooophorectomy [31]. For stage II, some authors recommend removal of a vaginal cuff because it is accompanied by a decrease in recidivism and improved survival [45]. The omentectomy is carried out in the papillary serous forms [31]. Pelvic lymphadenectomy is performed if the patient 
Table 9. Suggested treatment regimen.

\begin{tabular}{|c|c|c|}
\hline Stage & Surgery treatment & Post operative treatment \\
\hline IA G1/G2 & \multirow[t]{2}{*}{ Peritoneal cytology+hysterectomy+oophorectomy } & Surveillance \\
\hline IB G1/G2 & & Surveillance \pm brachytherapy if the tumor is close to the isthmus \\
\hline IA/IB G3 & \multirow{3}{*}{$\begin{array}{l}\text {-Peritoneal cytology+hysterectomy+oophorectomy+removal of a vaginal } \\
\text { cuff+pelvic lymphadenectomy } \\
\text {-Para-aortic lymphadenectomy if pelvic lymph node involvement }\end{array}$} & \multirow{3}{*}{$\begin{array}{l}\text { Vaginal brachytherapy } \pm \text { external radiotherapy } \\
\text { Chemotherapy to discuss }\end{array}$} \\
\hline $\mathrm{IC} \mathrm{G1/G2}$ & & \\
\hline IIA G1/G2 & & \\
\hline IC G3 & \multirow{5}{*}{$\begin{array}{l}\text {-Peritoneal cytology+hysterectomy+removal of a vaginal } \\
\text { cuff+oophorectomy+pelvic lymphadenectomy } \\
\text {-Para-aortic lymphadenectomy if adnexal stage III/para-aortic lymph node } \\
\text { macroscopically invaded } \\
\text {-Omentectomy if serous papillary carcinoma }\end{array}$} & \multirow{5}{*}{$\begin{array}{l}\text { external radiotherapy (pelvic } \pm \text { para-aortic if stage IIIC) } \pm \text { vaginal } \\
\text { brachytherapy }+ \text { chemotherapy }\end{array}$} \\
\hline IB G3 with emboli & & \\
\hline IIA G3 & & \\
\hline IIB/III & & \\
\hline Papillary serous or clear cell $>$ IA & & \\
\hline IVA & As complete as possible surgery & External radiotherapy+chemotherapy \\
\hline IVB & & Chemotherapy \pm palliative radiotherapy + supportive care \\
\hline
\end{tabular}

is in good condition and if the gesture is technically easy [31]. For stages III and IV, if the general condition of the woman allows, surgery as complete as possible is the best solution to improve overall survival. If the general condition is mediocre a complete hysterectomy through a laparotomywithout adnexal conservation is performed. Excision of all palpable lymph node is recommended [31]. Adjuvant radiotherapy after surgery is currently proposed depending on prognostic factors [31]. The interval surgery-radiotherapy is a capital prognostic factor, a retrospective study [46] showed that when this period exceeds six weeks it is a péjoratif prognostic factor of both specific survival $(p<0.005)$ and the local tumor control $(\mathrm{p}=0.06)$.

Chemotherapy was traditionally reserved for patients with metastatic cancer, but the detection of metastatic risk in certain subgroups and the positive results of chemotherapy in advanced forms led to its introduction in treatment protocols in patients with cancer risk of recurrence [47].

The treatment decision must be taken within a multidisciplinary meeting involving gynecologists, radiotherapists and carcinologues, and we propose the following regimen (Table 9).

\section{Conclusion}

At the end of this work and taking into account the literature data, endometrial cancer,an elderly woman cancer, must be searched in front of any abnormal functional signs and more specifically the peri-and postmenopausal bleedings especially in the presence of other risk factors. The best diagnosis mean is endometrial biopsy curettage performed under hysteroscopic control.

We recommend as part of the extension assessment to keep the examination under general anesthesia, the widespread practice of abdominal and pelvic MRI. For treatment we suggest to make decisions in collegial multidisciplinary consultations, to perform surgery immediately with adjuvant therapy tailored to risk factors and to discuss the necessity of a preoperative uterovaginal brachytherapy for stage.

\section{References}

1. FIGO stages 1988 revision (1989) Gyn Oncol 35: 125-127.

2. Le Digabel JF, Gariel C, Catala L, Dhainaut C, Madelenat P, et al. (2006) Atypical hyperplasia and endometrial carcinoma stage I in young women desiring pregnancy: conservative treatment is it possible? Results of a French multicenter study. Gynécologie Obstétriqueet Fértilité 34: 27-33.

3. Jemal A, Siegel R, Ward E, Hao Y, Xu J, et al. (2008) Cancer statistics, 2008. $C A$ Cancer J Clin 58: 71-96. [Crossref]

4. Ferlay J, Autier P, Boniol M, Heanue M, Colombet M, et al. (2007) Estimates of the cancer incidence and mortality in Europe in 2006. Ann Oncol 18: 581-592. [Crossref]

5. Sellami A, Sellami Boudawara T, Hsairi M, Jlidi R (2007) Cancer Registry of Southern Tunisia 2000-2002. Matisse Edition: 38-41.

6. Sellami A, Hsairi M, Achour N, Jlidi R (2002) Cancer Registry of Southern Tunisia 1997-1999. Matisse Edition 38-41.

7. Barakat RR, Lev G, Hummer AJ, Sonoda Y, Chi DS, et al. (2007) Twelve-year experience in the management of endometrial cancer: a change in surgical and postoperative radiation approaches. Gynecol Oncol 105: 150-156. [Crossref]

8. Disaia P, Creasman W (2002) Adenocarcinoma of the uterus Clinical gynecologic oncology $\left(5^{\text {th }}\right.$ edn $)$ St Louis: Mosby-Year Book: 137.

9. Parslov M, Lidegaard O, Klintorp S, Pedersen B, Jønsson L, et al. (2000) Risk factors among young women with endometrial cancer: a Danish case-control study. Am J Obstet Gynecol 182: 23-29. [Crossref]

10. Xu WH, Xiang YB, Ruan ZX, Zheng W, Cheng JR, et al. (2004) Menstrual and reproductive factors and endometrial cancer risk: Results from a population-based case-control study in urban Shanghai. Int J Cancer 108: 613-619. [Crossref]

11. Parazzini F, Negri E, La Vecchia C, Benzi G, Chiaffarino F, et al. (1998) Role of reproductive factors on the risk of endometrial cancer. Int $J$ Cancer 76: 784-786. [Crossref]

12. David M (2003) Review epidemiology of endometrial cancer. Reviews in Gyneacological Practice 3: 217-220.

13. Berstein L, Kvatchevskaya, Poroshina T (2004) Insulin resistance, its consequences for the clinical course of the disease, and possibilities of correction in endometrial cancer. J Cancer Res Clin Oncol 130: 687-693. [Crossref]

14. Chen LM, McGonigle KF, Berek JS (1999) Endometrial cancer: recent developments in evaluation and treatment. Oncology (Williston Park) 13: 1665-1670. [Crossref]

15. Smith RA, von Eschenbach AC, Wender R, Levin B, Byers T, et al. (2001) American Cancer Society guidelines for the early detection of cancer: update of early detection guidelines for prostate, colorectal, and endometrial cancers. Also: update 2001--testing for early lung cancer detection. CA Cancer J Clin 51: 38-75. [Crossref]

16. Descamps P, Galais G, Body G, Lansac J (1992) Cancer of the endometrium. Epidemiology, diagnosis, development, prognosis, treatment. Rev Prat 42: 2365-2371. [Crossref]

17. Furberg A, Thune I (2003) Metabolic abnormalities (hypertension, hyperglycemia and overweight), lifestyle (high energy intake and physical inactivity) and endometrial cancer risk in a Norwegian Cohort. Int J Cancer 104: 669-76. [Crossref]

18. Brown RC (1980) Staging of endometrial cancer. Int J Radiat Oncol Biol Phys 6: 355359.

19. Tabernero JM, Alonso MC, Ojeda B, Fuentes J, Balart J, et al. (1995) Endometrial cancer stages I and II. Analysis of survival and prognostic factors. Eur J Gynaecol Oncol 16: 18-25. [Crossref]

20. Parc YR, Halling KC, Burgart LJ, McDonnell SK, Schaid DJ, et al. (2000) Microsatellite instability and hMLH1/hMSH2 expression in young endometrial carcinoma patients: associations with family history and histopathology. Int $J$ Cancer 86: 60-66. [Crossref]

21. Kimura T, Kamiura S, Yamamoto T, Seino-Noda H, Ohira H, et al. (2004) Abnormal uterine bleeding and prognosis of endometrial cancer. Int J Gynaecol Obstet 85: 145150. [Crossref] 
22. Kodama J, Seki N, Ojima Y, Nakamura K, Hongo A, et al. (2007) Efficacy and prognostic implications of administering adjuvant chemotherapy to patients with endometrial cancer that is confined to the uterus. Eur J Obstet Gynecol Reprod Biol 131: 76-80. [Crossref]

23. Lambrou NC, Gómez-Marín O, Mirhashemi R, Beach H, Salom E, et al. (2004) Optimal surgical cytoreduction in patients with Stage III and Stage IV endometrial carcinoma: a study of morbidity and survival. Gynecol Oncol 93: 653-658. [Crossref]

24. Weber AM, Belinson JL, Bradley LD, Piedmonte MR (1997) Vaginal ultrasonography versus endometrial biopsy in women with postmenopausal bleeding. Am J Obstet Gynecol 177: 924-929. [Crossref]

25. Davidson KG, Dubinsky TJ (2003) Ultrasonographic evaluation of the endometrium in postmenopausal vaginal bleeding. Radiol Clin North Am 41: 769-780. [Crossref]

26. Lemercier E, Genevois A, Dacher JN (2000) The endometrium: what kind of imaging? J Radiol 81: 1857-1862. [Crossref]

27. Gull B (2003) Can ultrasound replaces dilatation and curettage? A longitudinal evaluation of postmenopausal bleeding and transvaginalsonographic measurement of the endometrium as predictors of endometrial cancer. Am J Obstet Gynecol 188: 401408. [Crossref]

28. Sousa R, Silvestre M, Almeida e Sousa L, Falcão F, Dias I, et al. (2001) Transvaginal ultrasonography and hysteroscopy in postmenopausal bleeding: a prospective study. Acta Obstet Gynecol Scand 80: 856-862. [Crossref]

29. Deckardt R, Lueken RP, Gallinat A, Möller CP, Busche D, et al. (2002) Comparison of transvaginal ultrasound, hysteroscopy, and dilatation and curettage in the diagnosis of abnormal vaginal bleeding and intrauterine pathology in perimenopausal and postmenopausal women. J Am Assoc Gynecol Laparosc 9: 277-282. [Crossref]

30. Clark TJ, Voit D, Gupta JK, Hyde C, Song F, et al. (2002) Accuracy of hysteroscopy in the diagnosis of endometrial cancer and hyperplasia: a systematic quantitative review. JAMA 288: 1610-1621. [Crossref]

31. (2001) French Comprehensive Cancer Centers Standards, options and recommendations for the management of patients with endometrial cancer SOR.

32. Lee EJ, Byun JY, Kim BS, Koong SE, Shinn KS (1999) Staging of early endometria carcinoma: assessment with T2-weighted and gadolinium-enhanced T1-weighted MR imaging. Radiographics 19: 937-945. [Crossref]

33. Undurraga M, Petignat P, Pelte MF, Jacob S, Dubuisson JB, et al. (2009) Magnetic resonance imaging to identify risk of lymph node metastasis in patients with endometrial cancer. Int J Gynaecol Obstet 104: 233-235. [Crossref]

34. Nakao Y, Yokoyama M, Hara K, Koyamatsu Y, Yasunaga M, et al. (2006) MR imaging in endometrial carcinoma as a diagnostic tool for the absence of myometrial invasion Gynecol Oncol 102: 343-347. [Crossref]

35. Chung HH, Kang SB, Cho JY, Kim JW, Park NH, et al. (2007) Accuracy of MR imaging for the prediction of myometrial invasion of endometrial carcinoma. Gynecol Oncol 104: 654-659. [Crossref]

36. Holland CM (2008) The role of radical surgery in carcinoma of the endometrium. Clin Oncol (R Coll Radiol) 20: 448-456. [Crossref]

37. Kinkel K (2006) Pitfalls in staging uterine neoplasm with imaging: a review. Abdom Imaging 31: 164-173. [Crossref]

38. Shepherd JH1 (1989) Revised FIGO staging for gynaecological cancer. Br J Obstet Gynaecol 96: 889-892. [Crossref]

39. Hoffstetter S, Brunaud C, Marchal C, Luporsi E, Guillemin F, et al. (2004) Preoperative brachytherapy for clinical stage I and II endometrial carcinoma: results from a series of 780 patients with a 10-year follow-up. Cancer Radiother 8: 178-187. [Crossref]

40. Barakat RR (1998) Contemporary issues in the management of endometrial cancer. $C A$ Cancer J Clin 48: 299-314. [Crossref]

41. Chan JK, Lin YG, Monk BJ, Tewari K, Bloss JD, et al. (2001) Vaginal hysterectomy as primary treatment of endometrial cancer in medically compromised women. Obstet Gynecol 97: 707-711. [Crossref]

42. Tozzi R, Malur S, Kfhler C, Schneider A (2004) Laparoscopy vs laparotomy in endometrial cancer: first analysis of survival of a randomized prospective study 35 th Annual SGO Meeting. Gynecol Oncol 92: 393-511.

43. Schwab KV, O’Malley DM, Fowler JM, Copeland LJ, Cohn DE (2009) Prospective evaluation of prognostic significance of the tumor-free distance from uterine serosa in surgically staged endometrial adenocarcinoma. Gynecol Oncol 112: 146-149. [Crossref]

44. Eltabbakh GH, Shamonki MI, Moody JM, Garafano LL (2000) Hysterectomy for obese women with endometrial cancer: laparoscopy or laparotomy? Gynecol Oncol 78: 329 335. [Crossref]

45. Arndt-Miercke H, Martin A, Briese V, Fietkau R, Gerber B, et al. (2008) Transection of vaginal cuff is an independent prognostic factor in stage I endometrial cancer. Eur $J$ Surg Oncol 34: 241-246. [Crossref]

46. Ahmad NR, Lanciano RM, Corn BW (1995) Prospective radiation therapy for surgically staged endometrial cancer: impact of time factors (overall treatment time and surgery to radiation interval) on outcome. Int J Radiat Oncol Biol Phys 33: 837-842.

47. Haie-Meder C, Paumier A, Lessard N, Morice P, Pautier P, et al. (2008) Adjuvant therapy and role of radiation therapy in advanced endometrial cancers. Cancer Radiother 12: 630-632. [Crossref] 